\title{
Tribological Behaviour of Phosphonium Based Ionic Liquid Blended with ZDDP
}

\author{
George Koshy, Bilal Abdul Samad, Abhinand Suresh, Mohammed Shameem, Anil Payyappalli Mana*
}

School of Mechanical Engineering, Vellore Institute of Technology, Vellore 632014, India

Corresponding Author Email: pmanil@vit.ac.in

https://doi.org/10.18280/jesa.520309

Received: 5 March 2019

Accepted: 17 May 2019

\section{Keywords:}

ionic liquid, ZDDP, tribofilm, friction, wear

\begin{abstract}
The chemical and physical characteristics of ionic liquids (IL) suggest that ILs when added as additives in lubricants offer better tribological properties than other conventional additives. However, the use of ionic liquids as such as a lubricant is not feasible. Phosphonium based ILs exhibit high miscibility and has been proved to be less corrosive when used as additives in small concentration. This study focuses on the behavior of Trihexyltetradecyl phosphonium bis (2,4,4-trimethylpentyl) phosphonate when blended with mineral base oil and engine oil. A comparison of its performance when used with ZDDP in diesel engine lubricant is also included. Tribological tests were carried out in a reciprocating wear test setup on AISI 52100 steel surfaces with a ball-on-flat geometry. Atomic force microscopy of the worn surfaces revealed the formation of a stable film with $3 \% \mathrm{IL}$ and $1 \% \mathrm{ZDDP}$ blend in base oil. Surface films formed with $1 \%$ and $5 \%$ IL and $1 \%$ ZDDP was observed to be severely worn due to unstable film formation and corrosive nature of the IL at $5 \%$ concentration.
\end{abstract}

\section{INTRODUCTION}

Since a century, automobile industries have been implementing the use of lubricant additives to minimize wear rate, improve efficiency, and hence prolong the life of an engine. Engine lubricants are intended to work in internal combustion chambers and are subjected to a wide range of fuels. Lubricants being chemically active in nature, when interacts with combustion products, results in their contamination, oxidation, and formation of deposits on contacting and rubbing surfaces. Thus the prolonged use of lubricants alone on the contact surfaces results in ramification to corrosion and wear, which directly affects the engine efficiency. Findings from several studies conducted in the past years say that the addition of engine oil additives act as defoamers, viscosity improvers, pour-point depressants, antiwear additives, extreme pressure additives, etc. Thus engine oil additives could serve as potential solution to the problem of reduced efficiencies.

Even though the use of ionic liquids was reported a century ago, its potential use was investigated in the 1970s and 1980s. Electrolytes in batteries were developed using, ionic liquids based on alkyl-substituted imidazolium and pyridinium cations, with halide or tetrahalogenoaluminate anions [1-2]. Imidazolium halogenoaluminate salts have physical properties such as viscosity, melting factor and acidity which could be adjusted with the aid of changing the alkyl substituents and the imidazolium/pyridinium and halide/halogenoaluminate ratios [3]. In 1992, Ionic Liquids neutral anions i.e. weakly coordinating in nature were obtained. Hexafluorophosphate $(\mathrm{PF}-6)$ and tetrafluoroborate $(\mathrm{BF}-4)$ are the neutral anions which have greater applications [4].

As mentioned above that ionic liquids usually exit in cationic and anionic form. Imidazolium is the most common cation that is used as room temperature ionic liquid (RTIL) lubricants in today's world. Imidazolium is being researched to study its effect on friction and wear [5-6]. Later, studies revealed that ammonium cations can be a substituent to imidazolium [7-8], then phosphonium cations and pyrrolidinium cations can be used since they show very efficient performance results. Figure 1 presents the various cations experimented by various researchers for use as lubricant additives

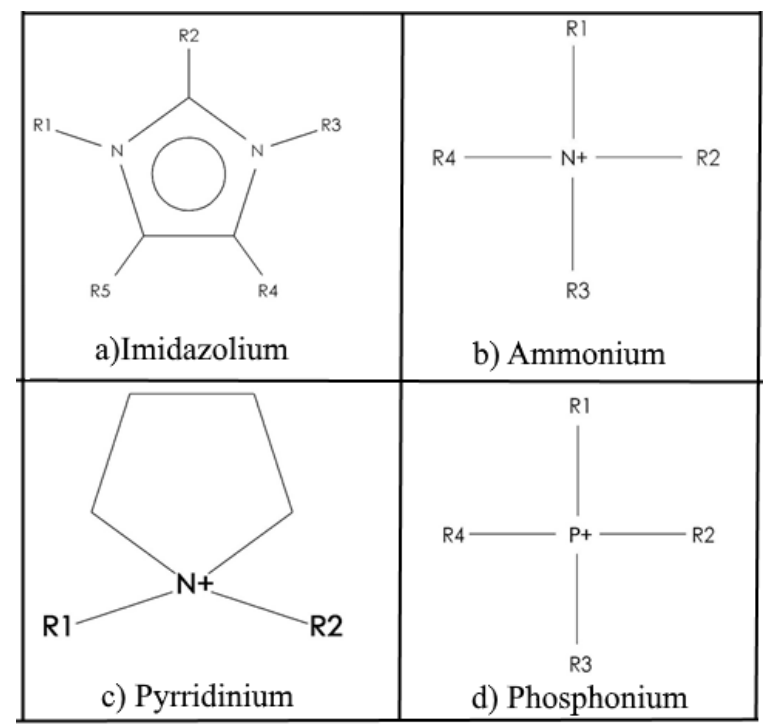

Figure 1. Chemical structure of various cations in ILs

Unlike cations these possess negative charges and includes various organic compounds such as tetrafluoroborate, hexafluorophosphate and others. Since PF6 and BF4 anions, in ILs, have the property to form protective tribofilms, other fluorine containing compounds like triflate (CF3SO3, Tf), bis (trifluoromethylsulfonyl) amide (NTf2) and perfluoroalkylphosphate (FAP) where investigated to check 
whether they possess the same property [7, 9-10]. Figure 2 presents the various anions experimented by various researchers for use as lubricant additives.

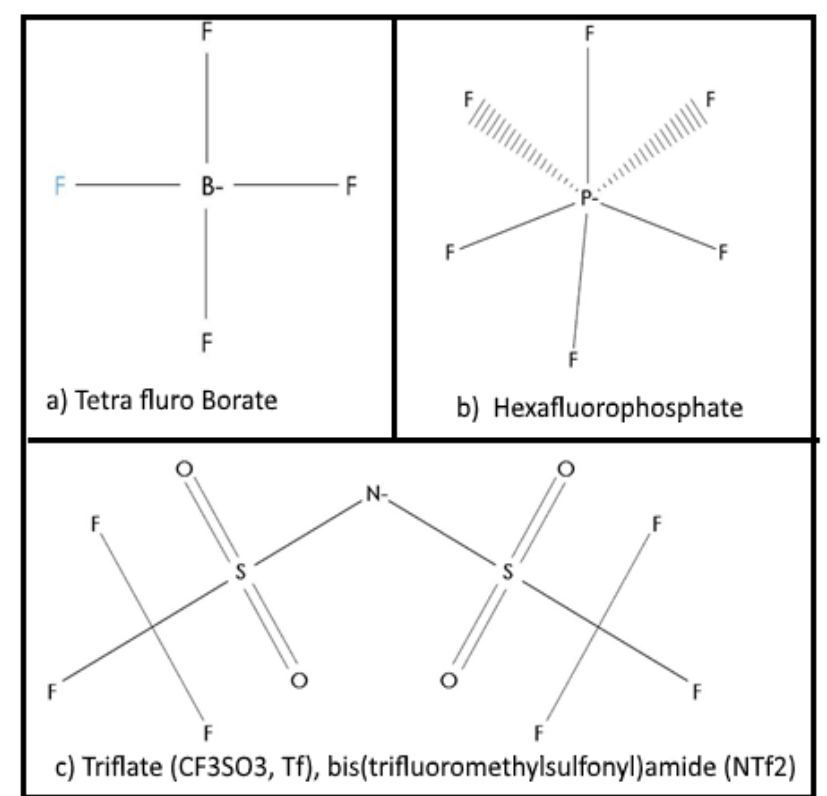

Figure 2. Chemical structure of various cations in ILs

Low volatility, low flammability and thermal stability are the few potential properties that ILs possess. Due to thermal stability ILs are able to withstand elevated temperatures and pressures involved in high frictions [11]. In fact, they have higher stability than conventional synthetic oil at 2000C [12]

Ionic liquids being salt in liquid state has a melting point below arbitrary temperatures, i.e. at 1000C. Though ordinary liquids like water and gasoline are made of electrically neutral molecules, ionic liquids are largely made of ions and shortlived ionic pairs [13-14]. Most of the ILS is composed of organic cations and a weakly coordinating anion. The chemical and physical properties can be tuned just by changing the anion-cation combination. This gives a great opportunity to obtain 'task-specific' ILs. Such different combinations made it responsible for increasing their number of applications. The growth of ILs since a decade has led to advances in technological applications [15].

A quantitative study in the past also depicts about the boundary film formation behaviour of oils with ILs [16]. According to it, sliding over the surface results in the formation of surface species and continuous sliding results in accumulation of these species. This results in the formation of boundary layers. The addition of phosphonium based Ionic Liquids into base oil leads to formation of boundary layers quickly, resulting in stable boundary formation. This is due to the increase in the amount of phosphorous element in the mixture which strengthen the affinity of ILs towards the formation of boundary layer over the metal surfaces as depicted in Figure 3. Thus a boundary layer reduces the plastic deformation and abrasive wear due to the presence of phosphonium based ILs in the engine oil [17].

Since the release of first paper that studied ILs as lubricants, ILs are used as universal lubricants for various systems. Few of the major studies that focused on ILs published that ILs can be used for particular applications like engine lubrication and micro-electrochemical machines (MEMs).

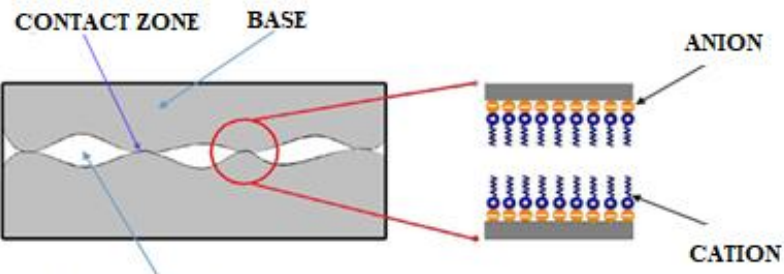

BOUNDARY LAYER

Figure 3. A schematic sketch of the boundary film formation on the contact surface

\section{EXPERIMENTAL PROCEDURE}

AISI 52100 steel bars were cut to the required size of $30 \mathrm{~mm} \times 30 \mathrm{~mm} \times 10 \mathrm{~mm}$ using a wire EDM. These pieces were then subjected to heat treatment as per the following procedure. The samples were heated to a temperature of $950 \mathrm{C}$ and then oil quenched. This is followed by tempering at $140 \mathrm{C}$ to obtain the required hardness. Heat treatment process ensures a regular crystalline structure and relieves the tension in the crystal than might occur during the casting. The heat treated AISI 52100 steel samples were used for the wear test. The counter specimens were bearing balls of $10 \mathrm{~mm}$ diameter. All the flat samples were tested for determining their hardness values. A schematic sketch of the flat sample is presented in Figure 4. The roughness of the samples was measured using a roughness tester and the values were noted. It was necessary to maintain the hardness and roughness of the samples within a comparable range so as to keep the error in experimental results to a bare minimum. Tribological tests were done using a reciprocating wear testing machine. The details of the machine are mentioned elsewhere [18]. In the machine, the upper specimen (ball) reciprocates on its counterpart, the flat surface. The wear test machine has a speed reduction mechanism that let us control the test parameters, and also the sample tray heater which let us control the operating temperature of the sample. Hence, operating parameters load, temperature and frequency can be varied. The stroke length was kept at $15 \mathrm{~mm}$ and the speed was set at $0.3 \mathrm{~m} / \mathrm{s}$. The operating temperature was set at $100{ }^{\circ} \mathrm{C}$ for all the test to have a test consistency. The operating parameters as per Table 1 were set and the experiments were performed. To study the progress of wear, each experiment was paused at specific intervals and wear scars were taken on aluminum replicas. The diameter of these impressions was measured using Dynolite macroscope and the increase in the impression diameters were used to calculate the progressive wear rate.

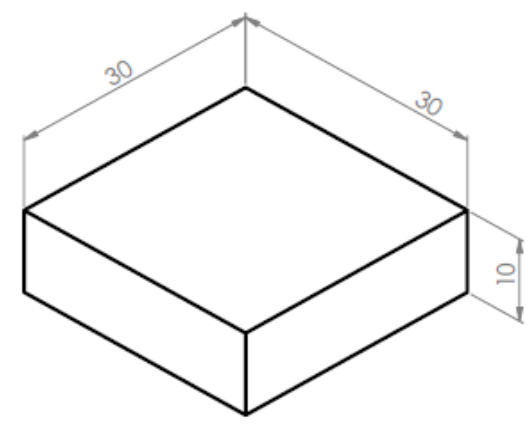

Figure 4. Sample dimensions (all dimensions in $\mathrm{mm}$ ) 
Table 1. Operating parameters

\begin{tabular}{ccccc}
\hline $\begin{array}{c}\text { Load } \\
(\mathbf{N})\end{array}$ & $\begin{array}{c}\text { Sliding } \\
\text { speed } \\
(\mathbf{m} / \mathbf{s})\end{array}$ & $\begin{array}{c}\text { Tempe- } \\
\text { rature } \\
\left({ }^{\circ} \mathbf{C}\right)\end{array}$ & $\begin{array}{c}\text { Test } \\
\text { duration } \\
(\text { minutes })\end{array}$ & $\begin{array}{c}\text { Speed } \\
(\mathbf{r p m})\end{array}$ \\
\hline 50 & 0.3 & $100 \pm 1$ & 120 & 600 \\
\hline
\end{tabular}

\subsection{Preparation of lubricants}

The tests were carried out on the samples at lubricated condition. For comparison, a total of 12 lubricant samples were prepared, including 3 samples of IL in mineral base oil, 3 samples of ZDDP in mineral base oil, 3 samples of IL and ZDDP blended in mineral base oil and finally 3 samples of IL in commercial diesel engine oil to understand its behavior as an additive in existing engine oils. These samples were made so as to study the effect of this IL as an additive in various mixtures and its behavior with already existing additives like ZDDP, defoamers etc. The samples of IL were prepared for various concentrations of $5 \%, 3 \%$ and $1 \%$ by volume. These specific concentrations were chosen in consideration of the fact that the many of the ILs are corrosive in nature above 5\% by volume [19]. Calculated amount of IL was blended thoroughly with $10 \mathrm{ml}$ of mineral base oil. $10 \mathrm{ml}$ of base oil is required for 10, 30, 50 micro $\mathrm{ml}$ of IL for obtaining 1\%, 3\%, $5 \%$ by volume respectively. This small fraction of addition was done with the help of a micro pipette with a wide nose as the IL was much denser and required a wide nose for the flow. The blended additives were mixed thoroughly to ensure a homogenous mixture. The samples of ZDDP were prepared for various concentrations of $1 \%, 0.5 \%$ and $0.1 \%$ by volume. Calculated amount of ZDDP was blended thoroughly with 5 $\mathrm{ml}$ of mineral base oil. Combination of ZDDP and IL were also used for testing to understand the interaction of IL with ZDDP. ZDDP additive was blended at various concentrations in $5 \mathrm{ml}$ of pre-prepared sample of 5\%,3\% and 1\% IL. The IL and engine oil mix was then prepared using commercial fully formulated engine oil. The IL was added to obtain various concentrations of $1 \%, 3 \%$ and $5 \%$ in engine oil. Table 2 presents the various concentrations of IL and ZDDP.

Table 2. Concentration of additives

\begin{tabular}{cccc}
\hline $\begin{array}{c}\text { IL in } \\
\text { Base oil }\end{array}$ & $\begin{array}{c}\text { ZDDP in } \\
\text { Base oil }\end{array}$ & $\begin{array}{c}\text { IL \& ZDDP in } \\
\text { Base oil }\end{array}$ & $\begin{array}{c}\text { IL in } \\
\text { Engine oil }\end{array}$ \\
\hline $1 \%$ & $1 \%$ & $1 \%$ IL + 1\% ZDDP & $1 \%$ \\
\hline $3 \%$ & $0.5 \%$ & $3 \%$ IL + 1\% ZDDP & $3 \%$ \\
\hline $5 \%$ & $0.1 \%$ & $5 \%$ IL + 1\% ZDDP & $5 \%$ \\
\hline
\end{tabular}

The tribological tests were carried out on a ball on flat geometry under lubricated condition. A $10 \mathrm{~mm}$ steel ball was fixed vertically on a ball holder in the reciprocating wear test machine. The sample that was well lubricated with the prepared sample of lubricant was placed in a $10 \mathrm{~mm} \times 10 \mathrm{~mm}$ sample holder and onto the tray. The ball and flat specimen were made to be in contact with each other. A load of $50 \mathrm{~N} \pm 1 \%$ was then applied onto the ball and plate contact using a load weight of $2.5 \mathrm{~kg}$. Once the required load is provided, the tension on the cable pulls down on the pin to apply force at the contact region. When the test is commenced, the ball reciprocates over the lower flat specimen at a sliding speed of $0.3 \mathrm{~m} / \mathrm{s}$. The wear scar diameter is measured as the diameter of the impression taken on aluminum foils at various intervals. This method is discussed elsewhere [19]. The wear rate was then calculated using relevant formulae. The frictional forces are obtained from the frictional force sensor and displayed in real time on a computer connected to the reciprocating wear test machine in the Winducom ${ }^{\circledR}$ software.

\subsection{Wear rate calculation}

The wear volume and wear rate were estimated as

$$
\text { Wear volume in } \mathrm{mm}^{3}, V=\frac{\pi h}{6}\left[\frac{3 d^{2}}{4}+h^{2}\right]
$$

where, $\mathrm{d}$ is the wear scar diameter in $\mathrm{mm}$ and $\mathrm{h}$ is the wear depth of scar on ball in $\mathrm{mm}$.

$$
\text { Depth of scar, } h=r-\sqrt{ }\left(r^{2}-\frac{d^{2}}{4}\right)
$$

where, $r$ is the radius of the steel ball

$$
\text { Wear rate, } Q=\frac{V}{X}
$$

where, $\mathrm{X}$ is the sliding distance in meter

$$
\text { Sliding distance, } X=0.002 * t * f * L
$$

where, $t$ is time in seconds, $f$ is reciprocating frequency in $\mathrm{Hz}$ and $L$ is the stroke length in $\mathrm{mm}$.

\section{RESULTS AND DISCUSSION}

\subsection{Analysis of friction and wear rate}

After the wear tests on specimens, the wear scars on the ball were measured using a measuring microscope. Wear volume and wear rates were calculated. Coefficient of friction data was compiled and analyzed. Scanning electron microscopy and atomic force microscopy analysis were carried out.

The effectiveness of the IL is evident at $3 \%$ concentration (Figure 5). At $1 \%$ concentration, the coefficient of friction is found to be varying in the range $0.16-0.19$, whereas at $3 \%$, it is more consistent. However, at $5 \%$, there are some minor fluctuations. The use of ILs beyond 5\% concentration has been proved to be ineffective by many researchers. [18, 20]. It is evident from Figure 6 that $1 \%$ ZDDP addition in mineral base oil is found to offer a lesser coefficient of friction than when compared to $0.1 \%$ and $0.5 \%$. Wear rate was found to be in the range $2.5 \times 10^{-5} \mathrm{~mm}^{3} / \mathrm{m}$. This is clearly in the mild wear range. Wear rate has been found to increase with more than $1 \%$ concentrations of ZDDP [21]. The formation of the poly phosphate boundary films is effective at $1 \%$ concentration [21-22]. Wear rate was found to increase marginally in the initial stage reaches about $3 \times 10^{-5} \mathrm{~mm}^{3} / \mathrm{m}$ then reduces considerably. This trend is typical of a running-in mechanism where the adjustment of the surfaces take place. During this period the wear rate will be high. Subsequent to this, the area of the contact zone increases and contact pressure reduces considerably. Wear rate also reduces. The effectiveness of lubrication of ILs is very much depended on the surface interactions and the various tribochemical reactions that happens at the interface. As the formation and removal of the reactive film is a cyclic process, the net effect on the friction and wear will be governed by the strength of the film to adhere on to the surface. 
When the IL was blended with engine oil at various concentrations and tested at the same conditions, its effectiveness was evident at $3 \%$ concentration in mineral base oil, in ZDDP and in engine oil than the other two concentrations (Figures 5, 6 and 7). This is reflected in the coefficient of friction and presents a clear indication that $3 \%$ IL is the optimum blend.

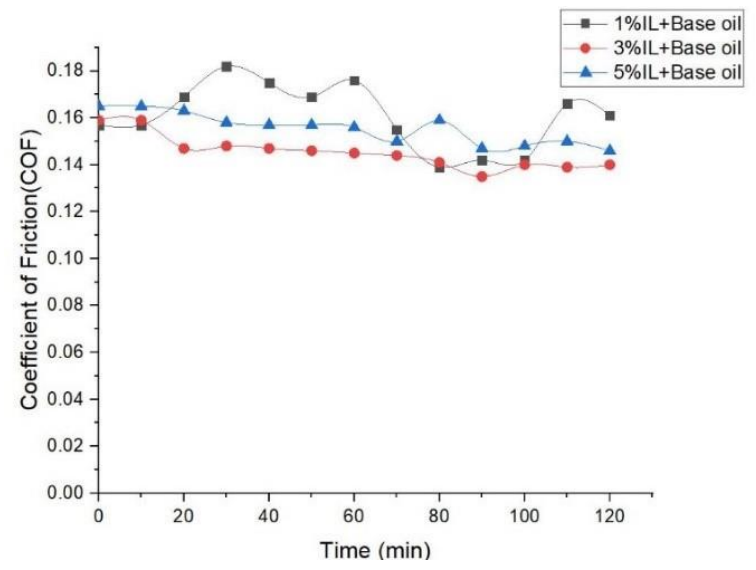

Figure 5. Results of the wear tests with $1 \%, 3 \%$ and $5 \%$ of IL in mineral base oil - Variation of coefficient of friction with time

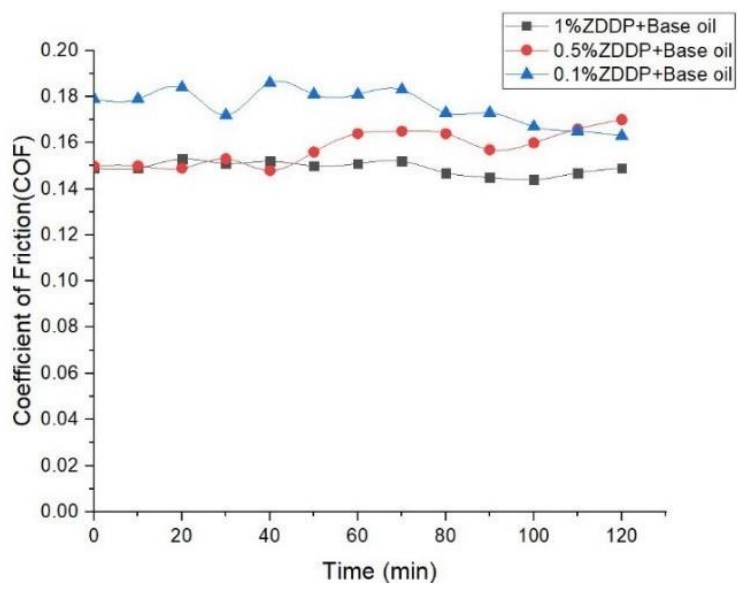

Figure 6. Results of the wear tests $1 \%, 0.5 \%$ \& $0.1 \%$ of ZDDP in mineral base oil - Variation of coefficient of friction with time

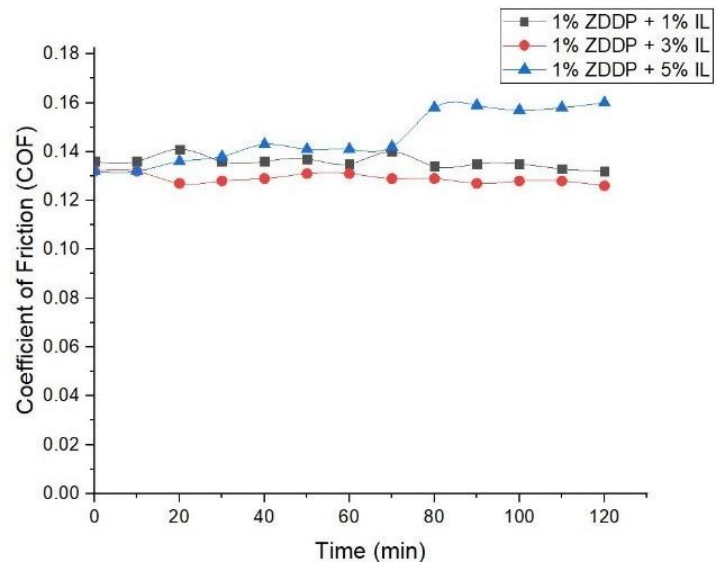

Figure 7. Results of the wear tests with $1 \%, 3 \%$ and $5 \%$ of IL and $1 \%$ of ZDDP in mineral base oil - Variation of coefficient of friction with time

\subsection{Surface morphology}

Preliminary observation of the sample shows formation of grooves in all the three samples in the direction of the ball sliding. The grooves formed in sample that was lubricated with $1 \% \mathrm{IL}$ and $1 \%$ ZDDP additive seems to have deeper wear tracks and deep grooves (Figure 8). A much closer examination of the sample under a higher magnification, the severe nature of the wear grooves was visible, the wear grooves were much deeper compared to other lubricant concentrations. Also at higher magnification shows the formation of flakes of the surface of the test samples. The $3 \%$ IL and 1\% ZDDP mix lubricant shows a fairly even film throughout the duration of test.

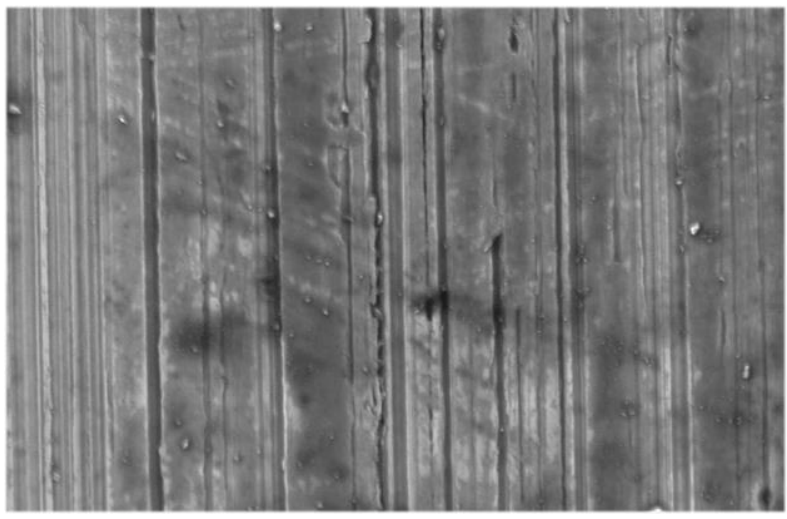

Figure 8. SEM image of specimens tested with lubricant containing $1 \%$ IL and $1 \%$ ZDDP (Magnification 2000X)

When viewing under a higher magnification the formation of the surface film is clearly visible with much lower groove formations and absence of flakes (Figure 9). The presence of IL along with ZDDP has influenced the anti-scuffing behavior and has resulted in a comparatively smooth surface as observed in the SEM (Figure 9).

Those specimens lubricated with $3 \%$ IL and 1\% ZDDP blended in mineral base oil showed a consistent film formation on the surface. While the friction coefficient observed was nearly in the boundary lubrication regime $(0.08-0.11)$, the wear rate indicates a low value and is a situation of mild wear (an order $<10^{-4}$ ).

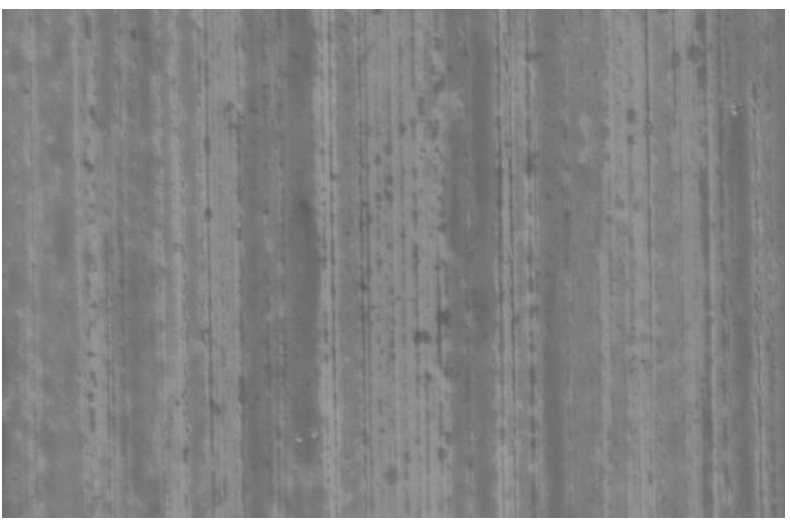

Figure 9. SEM image of specimens tested with lubricant containing $3 \%$ IL and 1\% ZDDP (Magnification 2000X)

The SEM images of the surfaces obtained with $5 \%$ IL and $1 \%$ ZDDP blends showed much deeper as well as patchy topography (Figure 10). The IL sample is known to be 
corrosive in nature at high concentration from previous literatures.

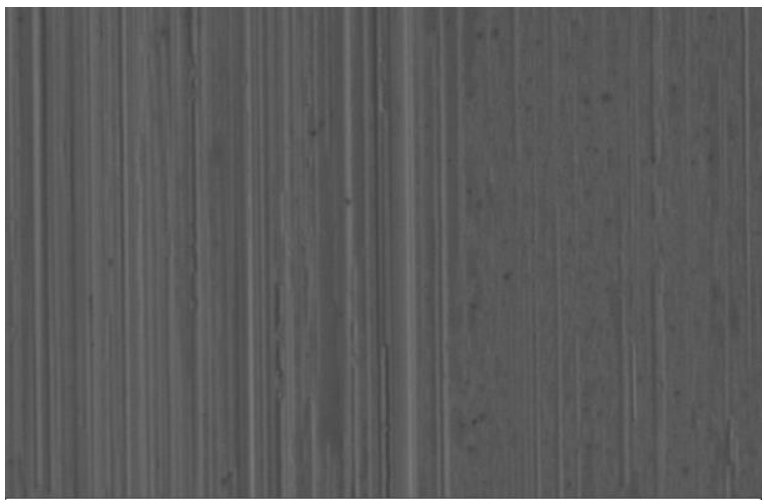

Figure 10. SEM image of specimens tested with lubricant containing $5 \%$ IL and $1 \%$ ZDDP (Magnification 2000X)

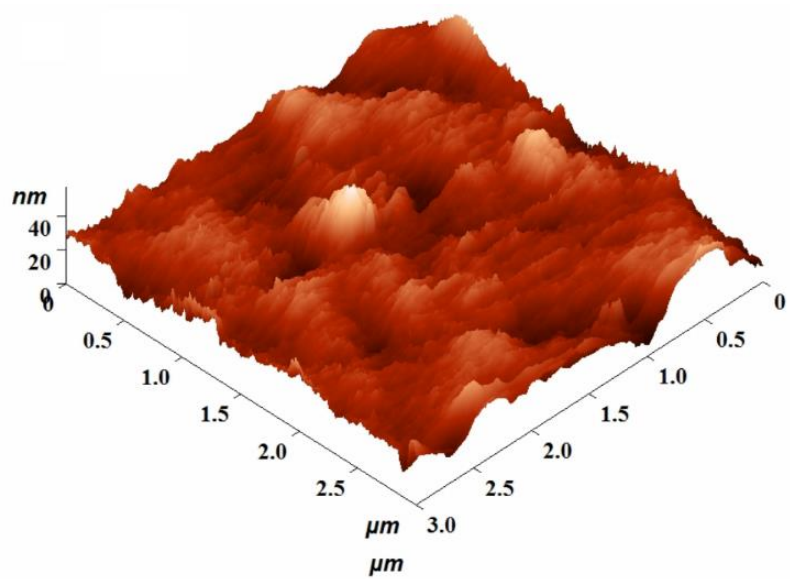

Figure 11. AFM image of specimens tested with lubricant containing $1 \%$ IL and $1 \%$ ZDDP

With $1 \%$ IL and $1 \%$ ZDDP in base oil, the AFM analysis shows a comparatively sharp peaks on the surface (Figure 11). This is an indication that the presence of IL or ZDDP has not affected the formation of a chemically reacted film.

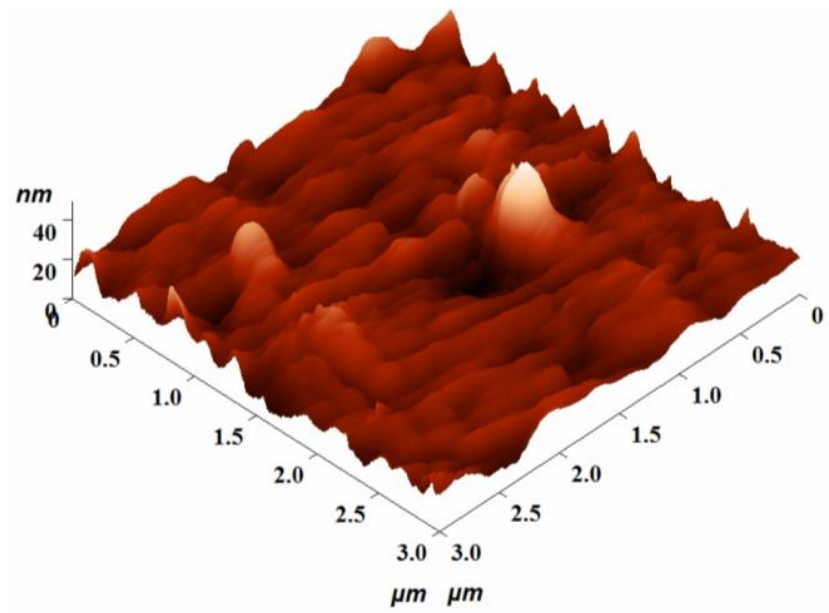

Figure 12. AFM image of specimens tested with lubricant containing $3 \%$ IL and $1 \%$ ZDDP

The AFM image of $3 \%$ IL (Figure 12) and $1 \%$ ZDDP it can be seen that the peaks are blunted and a continuous and smooth variation of the surface is observed. Even though a pad like reacted film formation was not observed in the case of ZDDP, isolated spongy mounts can be noticed. These are due to the reactive compounds formed on the surface [21].

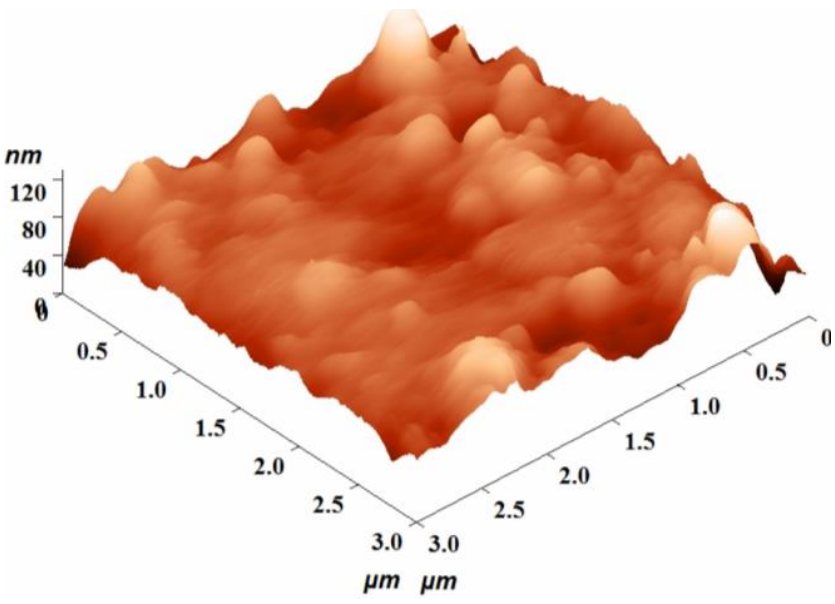

Figure 13. AFM image of specimens tested with lubricant containing $5 \%$ IL and $1 \%$ ZDDP

For $5 \%$ IL and $1 \%$ ZDDP as observed from the surface analysis (Figure 13), the topography shows a higher number of smaller and sharp peaks. This shows that increasing the percentage of IL in the blend to $5 \%$ has not aided any formation of film on the surface. Many researchers [22] have reported the formation of corrosive compounds with an increase of IL percentage affecting the friction and wear adversely. This study proves that $3 \%$ IL blend with ZDDP provides optimum friction as well as wear characteristics.

\section{CONCLUSION}

The IL, Trihexyltetradecyl phosphonium bis (2,4,4-trimethylpentyl) phosphinate was blended in various concentration of $1 \%, 3 \%, 5 \%$ in mineral base oil. $1 \%, 0.5 \%$, $0.1 \%$ concentration of ZDDP was mixed with mineral base oil to compare the results obtained from IL added lubricant. The wear tests were carried out on AISI 52100 steel samples that were hardened and lubricated with test solution. From the tests carried out it was evident that the $3 \%$ IL in base oil sample showed a promising result, having least $\mathrm{COF}$ and also the least wear rate compared to other samples. As for ZDDP samples the most optimum results were obtained from 1\% ZDDP in base oil concentration, having the lowest $\mathrm{COF}$ and wear rate. On comparing the results, it was observed that $3 \%$ IL had better lubricating properties as an additive.

The optimum for both the lubricant test solutions were identified and a mix of $1 \%$ ZDDP with $1 \%, 3 \%, 5 \%$ IL was made to find the behavior of IL and ZDDP as additive in engine oil. Testing of these new samples revealed that use of $1 \% \mathrm{ZDDP}$ and $3 \%$ IL has a better lubricating property than IL alone or ZDDP as an additive. The COF and wear rate values were significantly lower compared to other samples. When blended with fully formulated engine oil, it was observed that the test sample with $3 \%$ IL concentration in engine oil offered least coefficient of friction.

Further to analyze the interaction of the IL and ZDDP, samples were analyzed using Scanning Electron Microscope (SEM). The SEM images revealed scuffing and abrasive wear 
on sample solution with $5 \%$ and $1 \%$ IL. The $3 \%$ solution presented the lowest wear.

The AFM data revealed the formation of a stable film in $3 \%$ IL and $1 \%$ ZDDP solution. The film in $1 \%$ and $5 \%$ IL with $1 \%$ ZDDP was observed to be torn under the aggressive wear due to unstable film formation and corrosive nature of the IL at $5 \%$ concentration. The smoother film formed at $3 \%$ concentration confirms that the optimum additive concentration is $3 \%$.

\section{REFERENCES}

[1] Chum, H.L., Koch, V.R., Miller, L.L., Osteryoung, R.A. (1975). Electrochemical scrutiny of organometallic iron complexes and hexamethylbenzene in a room temperature molten salt. Journal of the American Chemical Society, 97(11): 3264-3265. https://doi.org/10.1021/ja00844a081

[2] Wilkes, J.S., Levisky, J.A., Wilson, R.A., Hussey, C.L. (1982). Dialkylimidazolium chloroaluminate melts: A new class of room-temperature ionic liquids for electrochemistry, spectroscopy and synthesis. Inorganic Chemistry, 21(3): 1263-1264. https://doi.org/10.1021/ic00133a078

[3] Gale, R.J., Osteryoung, R.A. (1979). Potentiometric investigation of dialuminum heptachloride formation in aluminum chloride-1-butylpyridinium chloride mixtures. Inorganic Chemistry, 18(6): 1603-1605. https://doi.org/10.1021/ic50196a044

[4] Wilkes, J.S., Zaworotko, M.J. (1992). Air and water stable 1-ethyl-3-methylimidazolium based ionic liquids. Journal of the Chemical Society, Chemical Communications, (13): 965-967. https://doi.org/10.1021/ic50196a044

[5] Liu, W., Ye, C., Gong, Q., Wang, H., Wang, P. (2002). Tribological performance of room-temperature ionic liquids as lubricant. Tribology Letters, 13(2): 81-85. https://doi.org/10.1023/A:102014851

[6] Wang, H., Lu, Q., Ye, C., Liu, W., Cui, Z. (2004). Friction and wear behaviors of ionic liquid of alkylimidazolium hexafluorophosphates as lubricants for steel/steel contact. Wear, 256(1-2): 44-48. https://doi.org/10.1016/s0043-1648 (03)00255-2

[7] Minami, I., Kita, M., Kubo, T., Nanao, H., Mori, S. (2008). The tribological properties of ionic liquids composed of trifluorotris (pentafluoroethyl) phosphate as a hydrophobic anion. Tribology Letters, 30(3): 215-223. https://doi.org/10.1007/s11249-008-9329-y

[8] Iglesias, P., Bermúdez, M.D., Carrion, F.J., MartınezNicolás, G. (2004). Friction and wear of aluminium-steel contacts lubricated with ordered fluids-neutral and ionic liquid crystals as oil additives. Wear, 256(3-4): 386-392. https://doi.org/10.1016/S0043-1648(03)00442-3

[9] Lu, Q., Wang, H., Ye, C., Liu, W., Xue, Q. (2004). Room temperature ionic liquid 1-ethyl-3-hexylimidazolium-bis (trifluoromethylsulfonyl)-imide as lubricant for steel- steel contact. Tribology International, 37(7): 547-552. https://doi.org/10.1016/j.triboint.2003.12.003

[10] Qu, J., Truhan, J.J., Dai, S., Luo, H., Blau, P.J. (2006). Ionic liquids with ammonium cations as lubricants or additives. Tribology Letters, 22(3): 207-214. https://doi.org/10.1007/s11249-006-9081-0

[11] Ye, C.F., Liu, W.M., Chen, Y.X., Yu, L.G. (2001). Room-temperature ionic liquids: A novel versatile lubricant. Chemical Communications, (21): 2244-2245. https://doi.org/10.1039/B106935G

[12] Minami, I. (2009). Ionic liquids in tribology. Molecules, 14(6): 2286-2305 https://doi.org/10.3390/molecules 14062286

[13] Welton, T. (1999). Room-temperature ionic liquids. Solvents for synthesis and catalysis. Chemical Reviews, 99(8): 2071-2084. https://doi.org/10.1021/cr980032t

[14] Endres, F., El Abedin, S.Z. (2006). Air and water stable ionic liquids in physical chemistry. Physical Chemistry Chemical Physics, 8(18): 2101-2116. https://doi.org/10.1039/B600519P

[15] Silvester, D.S., Compton, R.G. (2006). Electrochemistry in room temperature ionic liquids: A review and some possible applications. Zeitschrift für Physikalische Chemie, 220(10): 1247-1274 https://doi.org/10.1524/zpch.2006.220.10.124

[16] Yamaguchi, E.S., Ryason, P.R., Yeh, S.W., Hansen, T.P. (1998). Boundary film formation by ZnDTPs and detergents using ECR. Tribology Transactions, 41(2): 262-272. https://doi.org/10.1080/10402009808983747

[17] Anand, M., Hadfield, M., Viesca, J.L., Thomas, B., González, R., Cantrill, R., Hernández Battez, A. (2016). Assessing boundary film forming behavior of phosphonium ionic liquids as engine lubricant additives. Lubricants, $4(2)$ : 17. https://doi.org/10.3390/lubricants4020017

[18] Anil, P.M., Rajamohan, V. (2017). Influence of surface roughness and ZDDP additive on the friction and wear of reciprocating sliding surfaces at high contact pressures. Industrial Lubrication and Tribology. https://doi.org/10.1108/ILT-05-2016-0111

[19] Grace, J., Vysochanska, S., Lodge, J., Iglesias, P. (2015). Ionic liquids as additives of coffee bean oil in steel-steel contacts. Lubricants, 3(4): 637-649. https://doi.org/10.3390/lubricants3040637

[20] Bermúdez, M.D., Jiménez, A.E., Sanes, J., Carrión, F.J. (2009). Ionic liquids as advanced lubricant fluids. Molecules, $14(8)$ 2 2888-2908. https://doi.org/10.3390/molecules14082888

[21] Zhang, Z., Yamaguchi, E.S., Kasrai, M., Bancroft, G.M. (2005). Tribofilms generated from ZDDP and DDP on steel surfaces: Part 1, growth, wear and morphology. Tribology Letters, 19(3): 211-220. https://doi.org/10.1007/s11249-005-6148-2

[22] Spikes, H. (2004). The history and mechanisms of ZDDP. Tribology Letters, 17(3): 469-489. https://doi.org/10.1023/B:TRIL.0000044495.26882.b5 